\title{
A Crunching Colon: Rectal Bezoar Caused by Pumpkin Seed Consumption
}

\author{
Janaki R. Manne, MD; Venu M. Rangu, MD; \\ Uma Maheswara R. Motapothula, MD; and Matthew C. Hall, MD
}

\begin{abstract}
Rectal seed bezoars are an uncommon cause of fecal impaction, particularly in the United States. Although the literature has reported several cases of phytobezoars composed of various types of seeds, bezoars formed of pumpkin seeds have rarely been reported. We report a case of a man, aged 62 years, with a rectal bezoar composed of pumpkin seeds with complications necessitating extensive treatment, including manual disimpaction and colonoscopy.
\end{abstract}

Keywords: Bezoar; Fecal impaction; Seed consumption; Stercoral

Corresponding Author:

Janaki R. Manne, MD

Hospitalist, Department of Internal Medicine

Marshfield Clinic

1000 North Oak Ave

Marshfield, WI 54449 USA

Tel: $715-387-5537$

Fax: 715-389-5757

Email: manne.janaki@marshfieldclinic.org

Received: April 14, 2011

Revised: August 4, 20II

Accepted: August 4, 2011

doi: $10.3121 / \mathrm{cmr} .2011 .1016$
$\mathrm{R}$ in the United States. They are reportedly more common in the Middle East where they constitute the most common cause of fecal impaction requiring hospitalization, likely due to dietary habits that include seed consumption. ${ }^{1}$ There have been several reports of phytobezoars composed of various types of seeds (such as sunflower and prickly pear seeds) ${ }^{1}$ however, pumpkin seeds have rarely been implicated in bezoar formation. Mirza et $\mathrm{al}^{2}$ reported a case of a rectal bezoar due to pumpkin seeds in a Middle Eastern child; however, we are unaware of any such report in the adult population, particularly in the United States.

\section{Case Report}

A man, aged 62 years, with no significant past medical history presented with rectal discomfort, pain, and spasms. He had the urge to defecate but was unable to push anything out. He reported normal bowel movements up to two days prior. Since that time his discomfort had worsened, and he was unable to pass anything rectally. History was negative for nausea, vomiting, diarrhea, hematemesis, melena, and hematochezia. He reported that he had been out of town working long hours over the weekend. During that time his eating schedule had been altered, and he had consumed a large quantity of pumpkin seeds. He reported never having had problems of this nature before and had never had problems with diarrhea, constipation, or blood in his stool.

Physical examination revealed an abdomen that was soft, non-tender, and without organomegaly. Bowel sounds were normal. Rectal examination showed anal spasm and a hard mass with prickly sharp edges and positive "colonic crunch" sign. ${ }^{3}$ The colonic crunch sign is defined as the palpation of a prickly mass on digital rectal examination and can be found with sunflower seed bezoar and lithobezoar. ${ }^{3}$ Plain abdominal films showed air with a limited amount of fecal material proximal to the rectum (figure 1). 


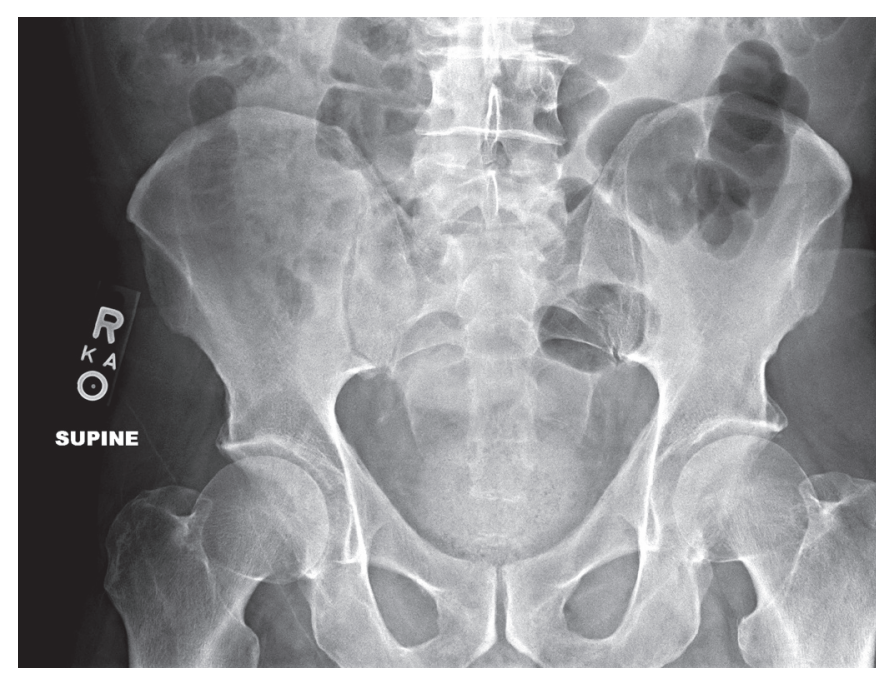

Figure 1. Plain abdominal film showing air with a limited amount of fecal material proximal to the rectum.

\section{Diagnosis and Management}

History, clinical examination, and radiographs were consistent with rectal bezoar due to pumpkin seeds. The patient was given several tap water enemas resulting in return of liquid brown stool. He continued to have rectal discomfort and was then given two liters of GoLYTELY (polyethylene glycol). He continued to have watery liquid brown returns with no substantive stool.

Flexible sigmoidoscopy was performed under sedation and showed pumpkin seeds in a very large aggregate. Roth retrieval nets and baskets were used six times to remove approximately $60 \%$ of the pumpkin seed bezoar in the rectal vault. Underneath the bezoar, a shallow stercoral ulceration involving the majority of the circumference of the rectum was found. An attempt to use a banding hood to suction large portions of the bezoar into the tip was unsuccessful. Manual finger massage was performed at the area of the bezoar formation until it broke into smaller pieces.

Finally, colonoscopy was performed to remove the remaining seeds. A large aggregate of pumpkin seed material was seen in the rectum (figure 2 and figure 3). Using an anoscope and forceps, a large amount of pumpkin seed material was removed.

Using the Roth retrieval net, the remaining pumpkin seeds were removed and cleared from the rectum and sigmoid portion of the colon (figure 4). A circumferential stercoral ulceration was seen in the rectum with marked edema and erythema (figure 5). Biopsies were taken of this area which subsequently returned as negative. The patient's symptoms significantly improved, and he was discharged on a high fiber diet. Repeat sigmoidoscopy two months later was normal.

\section{Discussion}

Bezoars composed of a variety of substances have been described in the literature ${ }^{1,2-7}$ and are classified based on their composition. Commonly described bezoars include phytobezoars (composed of nondigestable food materials such as seeds and pits), trichobezoars (composed of hair), lactobezoars (composed of lactose), and pharmacobezoars (composed of medications). ${ }^{8}$ The reason for the formation of a bezoar is believed to be essentially mechanical, depending upon the insoluble and indigestible content. Bezoars grow by the continued ingestion of food rich in cellulose and other indigestible materials. They are most commonly seen in the stomach, and rarely in the colon and rectum. Common clinical manifestations include nausea, vomiting, anorexia, weight loss, constipation, and obstipation. The complications of bezoars include obstruction, ulceration, hemorrhage, and perforation..$^{2-7}$

Stercoral ulceration, first described by Berry in $1894,{ }^{9}$ is an ulcer produced by pressure necrosis from a fecal mass that occurs most commonly as an isolated lesion in the rectum and sigmoid colon. ${ }^{9,10}$ The lesion usually occurs in elderly patients with a history of chronic constipation. Although the principal complications of stercoral ulceration include perforation and

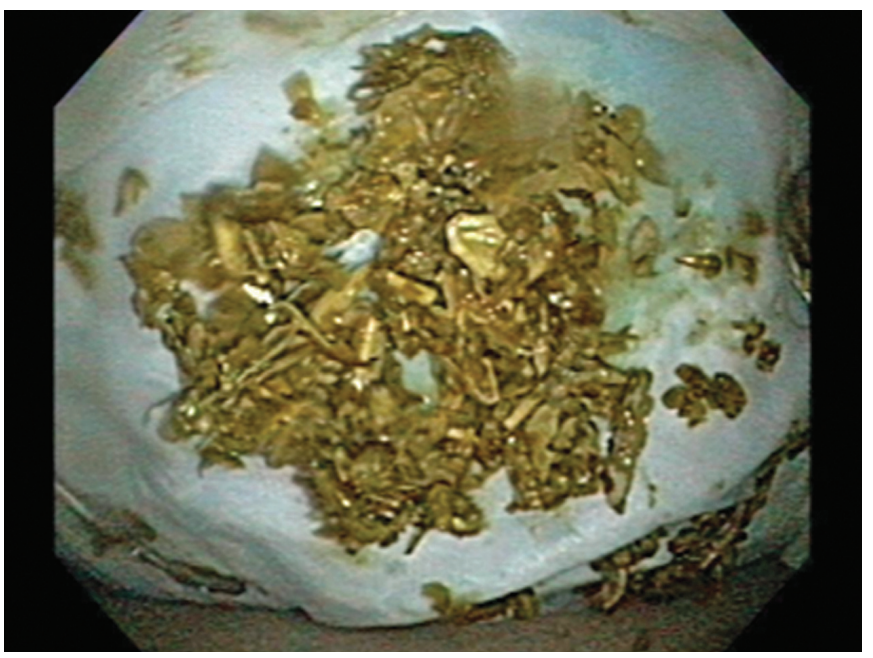

Figure 2. Colonoscopy image of pumpkin seeds with intact shells.

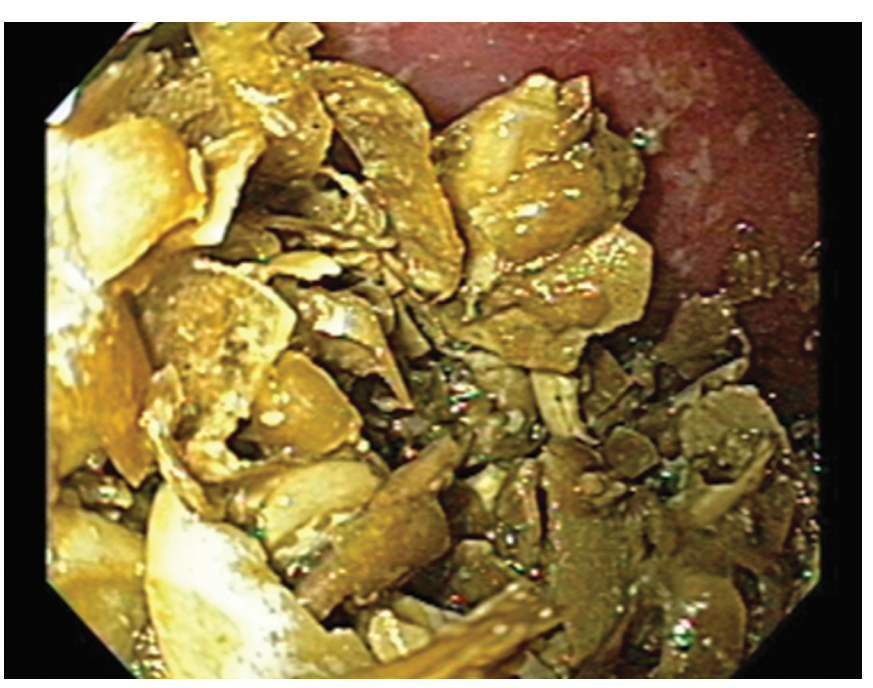

Figure 3. Colonoscopy image of pumpkin seed bezoar in the rectum. 


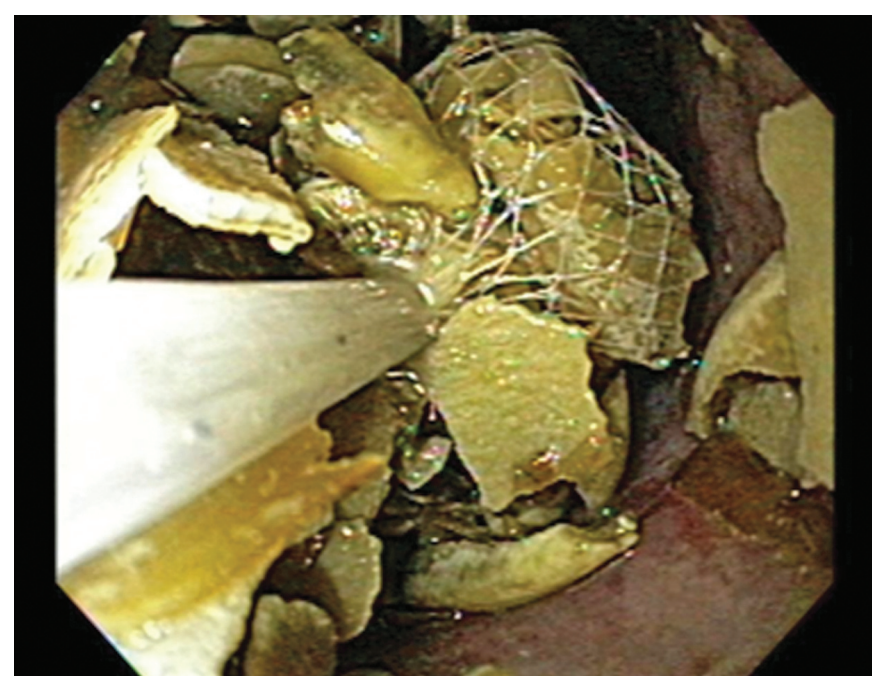

Figure 4. Colonoscopic retrieval of pumpkin seeds with retrieval net.

hemorrhage, there have been few reports of lower gastrointestinal bleeding related to the lesion. Treatment of stercoral ulceration varies depending upon severity of symptoms. ${ }^{10-13}$

Therapy for bezoars is based on the composition of the concretion and the underlying pathophysiologic process. Available treatment options are chemical dissolution, endoscopy, and surgery. ${ }^{8}$ There are no prospective studies evaluating medical treatment in the form of chemical dissolution. Different endoscopic methods have been reported including water jet, forceps, snares, and baskets. ${ }^{4,8}$

Although bezoars are uncommon, physicians should learn to recognize the symptoms in order to provide appropriate therapy. In patients presenting with fecal impaction, a thorough questioning of their dietary habits should be undertaken and, particularly with a failed response to laxatives, the possibility of rectal seed bezoar should be considered. Management may

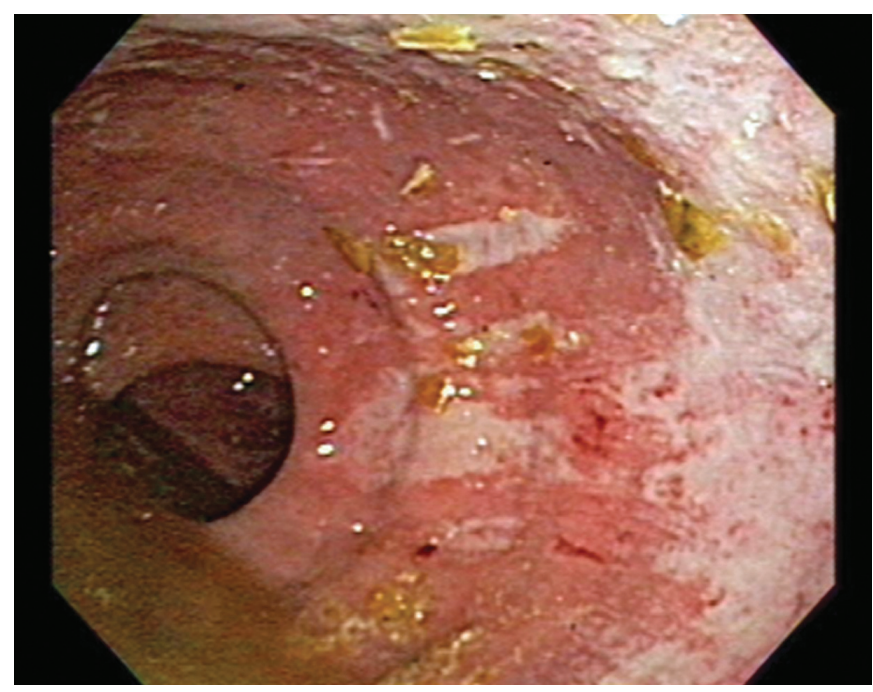

Figure 5. Colonoscopy image of stercoral ulcer. require manual disimpaction and even endoscopic retrieval. Once the bezoar has been removed, preventive therapy should be implemented to avoid recurrence. ${ }^{8}$ Patients should be encouraged to increase their water intake, to appropriately alter their diet, and to chew their food carefully, since inadequate chewing, swallowing whole seeds (such as those in oranges), or eating seeds without removing the shell may lead to their impaction as bezoars.

\section{Acknowledgements}

The authors thank staff of the Marshfield Clinic's Department of Gastroenterology for their valuable contribution to this patient's evaluation and management. The authors also thank the Marshfield Clinic Research Foundation's Office of Scientific Writing and Publication for editorial assistance in the preparation of this manuscript.

\section{References}

1. Eitan A, Bickel A, Katz IM. Fecal impaction in adults: report of 30 cases of seed bezoars in the rectum. Dis Colon Rectum 2006;49:1768-1771.

2. Mirza MS, Al-Wahibi K, Baloch S, Al-Qadhi H. Rectal bezoars due to pumpkin seeds. Trop Doct 2009;39:54-55.

3. Melchreit R, McGowan G, Hyams JS. "Colonic crunch" sign in sunflower seed bezoar. N Engl J Med 1984;310:1748-1749.

4. Purcell L, Gremse DA. Sunflower seed bezoar leading to fecal impaction. South Med J 1995;88:87-88.

5. Steinberg JM, Eitan A. Prickly pear fruit bezoar presenting as rectal perforation in an elderly patient. Int J Colorectal Dis 2003;18:365-367.

6. Efrati Y, Freud E, Serour F, Klin B. Phytobezoar-induced ileal and colonic obstruction in children. J Pediatr Gastroenterol Nutr 1997;25:214-216.

7. Moons P, Dikken FP, Raven EE, Tan KG. [Severe obstipation due to eating unshelled sunflower seeds] [Article in Dutch]. Ned Tijdschr Geneeskd 2000;144:1878-1879.

8. Andrus CH, Ponsky JL. Bezoars: classification, pathophysiology, and treatment. Am J Gastroenterol 1988;83:476-478.

9. Berry J. Dilatation and rupture of the sigmoid flexure. BMJ $1894 ; 1: 301$

10. Huang CC, Wang IF, Chiu HH. Lower gastrointestinal bleeding caused by stercoral ulcer. CMAJ 2010 Dec 20. [Epub ahead of print]

11. Madan P, Bhayana S, Chandra P, Hughes JI. Lower gastrointestinal bleeding: association with Sevelamer use. World J Gastroenterol 2008;14:2615-2616.

12. Knigge KL, Katon RM. Massive hematochezia from a visible vessel within a stercoral ulcer: effective endoscopic therapy. Gastrointest Endosc 1997;46:369-370.

13. Matsushita M, Hajiro K, Takakuwa H, Nishio A, Tominaga M. Bleeding stercoral ulcer with visible vessels: effective endoscopic injection therapy without electrocoagulation. Gastrointest Endosc 1998;48:559.

\section{Author Affiliations}

Janaki R. Manne, MD*; Venu M. Rangu, MD*; Uma

Maheswara R. Motapothula, MD*; Matthew C. Hall, $M D^{*}$

"Department of Internal Medicine, Marshfield Clinic,

Marshfield, WI, USA

'Department of Infectious Medicine, Marshfield Clinic, Marshfield, WI, USA 